\title{
Assessment of adoption potential for smallholder conservation agriculture in Pandamatenga vertisols of northern Botswana
}

\author{
Kapweke Kandondi ${ }^{1}$, Davis Samzala Marumo ${ }^{2}$, Benedict Kayombo $1{ }^{1}{ }^{*}$ and Thembeka Mpuisang 1 \\ ${ }_{1}$ Department of Agricultural and Biosystems Engineering, Botswana University of Agriculture and Natural Resources, \\ Private Bag 0027, Gaborone, Botswana. \\ 2 Department of Agricultural Economics and Rural Development, Botswana University of Agriculture and Natural \\ Resources, Private Bag 0027, Gaborone, Botswana.
}

World Journal of Advanced Engineering Technology and Sciences, 2021, 04(01), 001-010

Publication history: Received on 19 September 2021; revised on 27 October 2021; accepted on 29 October 2021

Article DOI: https://doi.org/10.30574/wjaets.2021.4.1.0070

\begin{abstract}
The adoption of conservation agriculture among small-scale farmers is still low despite the proven economic and environmental benefits of the technology. This study was conducted at Pandamatenga of Chobe District in northern Botswana. The main aim of the study was to determine the factors that influence the adoption of Conservation Agriculture (CA) in the study area. A structured questionnaire was used for the collection of the socio- economic and demographic characteristics of the sampled smallholder rainfed farmers. The socio - economic characteristics of the smallholder rainfed farmers included land holding size (ha), labour availability, livestock possession, education level, and farming experience. Demographic characteristics considered in the study included smallholder rainfed farmers' age, marital status, gender, and average number of family members in the household. Data was analysed using descriptive statistics and the logistic regression model. The results have shown that gender and farm size had a significant influence on smallholder rainfed farmers' decision to adopt CA technologies in Pandamatenga. Smallholder rainfed farmers had a positive perception and a high level of acceptance of CA technologies that were tried in their area.
\end{abstract}

Keywords: Adoption; Conservation Agriculture technologies; Smallholder rainfed farmers Adoption; Conservation Agriculture technologies; Smallholder rainfed farmers

\section{Introduction}

The adoption of conservation agricultural technologies in developing countries including Botswana has attracted considerable attention because it can provide the basis for increasing production and income. Support programmes such as Integrated Support Programme for Arable Agricultural Development (ISPAAD) and Agriculture Services Support Project (ASSP) were established to help farmers adopt and implement improved agricultural technologies across Botswana. The Department of Agricultural Research is committed to develop appropriate and environmentally friendly agricultural technologies in support of sustainable and competitive agriculture to contribute to food security, poverty alleviation and socio-economic growth. Although the farming systems approach is being questioned, it remains one of the solutions to address some of the challenges faced by smallholder rainfed farmers in Botswana.

Rainfed agriculture plays an important role in rural development by providing food, employment and income for the majority of rural dwellers in Botswana [1]. The Government of Botswana has placed high priority on the development of agriculture in Pandamatenga because of the area's inherent potential to contribute to food security, poverty alleviation and socio - economic growth. Vertisols such as those found in the Pandamatenga region have a high crop

\footnotetext{
${ }^{*}$ Corresponding author: Benedict Kayombo

Department of Agricultural and Biosystems Engineering, Botswana University of Agriculture and Natural Resources, Private Bag 0027, Gaborone, Botswana.
} 
production potential. Farmers are however unable to manage these types of soils because of their unique properties that require a careful special management to translate their high potential fertility into successful crop production. Furthermore, most farmers in Pandamatenga practice conventional tillage where the whole field is ploughed using a mouldboard followed by harrowing. These repeated machinery operations are known to destroy soil structure. This leads to problems of soil degradation and compaction and result in an increased exposure of soils to high intensity storms [2]. The long-term effect of which is the decline in crop yields.

To mitigate the physical constraints of vertisolic properties, some organizations such as the International Crops Research Institute for the Semi-arid Tropics (ICRISAT) and International Livestock Centre for Africa (ILCA) have been promoting alternative methods of crop production especially in vertisols. These farming systems such as CA enhance productivity while conserving soil and water. According to Food and Agriculture Organization (FAO) [3], conservation farming or CA is an approach to managing agro-ecosystems for improved and sustained productivity, increased profits and food security while preserving and enhancing the resources base and the environment.

Conservation Agriculture is characterized by three linked principles namely, continuous minimum mechanical soil disturbance, permanent organic soil cover and diversification of crop species grown in sequence and/or associations. Under favourable climatic conditions and appropriate management, vertisols have proved to be productive and capable of producing a much greater contribution to food production [4]. However, the impact of the technology will only be realized if most smallholder rainfed farmers accept and adopt the technology. The literature highlights several benefits of CA, amongst which are an improvement in soil fertility, labour savings, improved efficiency in water use, an increase in productivity and environmental sustainability [5]. The extent to which CA technologies have been adopted and the socio-economic factors that influence their adoption have not been documented especially in Pandamatenga. There are several studies from other countries that have assessed the factors that influence farmers' decision to adopt CA technologies [6, 7].

The specific objectives of this study were, therefore, to: (1) describe the socio economic and demographic characteristics of smallholder rainfed farmers in Pandamatenga region, (2) assess smallholder rainfed farmers' perception and acceptance of CA technologies [namely No Tillage (NT), No Tillage + Mulch (NT+M), Minimum Tillage (MT) and Broad Bed and Furrow (BBF)] in the Pandamatenga region, and (3) identify social and economic factors that influence smallholder rainfed farmers' decisions to adopt different CA technologies.

\section{Material and methods}

\subsection{Description of the study Area}

The study was based at Pandamatenga. Pandamatenga lies in the northern part of Botswana between latitude 18우 $32^{\prime}$ South, and longitude 250 38' East and it covers an area of 280, 380ha (Figure 1). The Pandamatenga farms (Figure 2) cover only 25,074 ha of this total land area [2].



Figure 1 Location of study area in Africa

The climate for the Pandamatenga region is semiarid characterized by hot and moist summers and dry mild winters. Rainfall is derived from convective processes and is highly variable even over small distances and averages $600 \mathrm{~mm}$ annually. Almost all rain falls between October and April, with December, January and February being the peak months. A substantial proportion of this rain falls in short duration of high intensity storms, thus, leading to high run-on into some farms, which become flooded instantly. Maximum temperatures range between $26^{\circ} \mathrm{C}$ to $34^{\circ} \mathrm{C}$ and are experienced 
between October to March. Minimum temperatures range between $11^{\circ} \mathrm{C}$ to $20^{\circ} \mathrm{C}$ and are experienced between November and July. The vegetation is extensive grassland savannah in association with mopane (Colophospermum mopane) and acacia species [8].

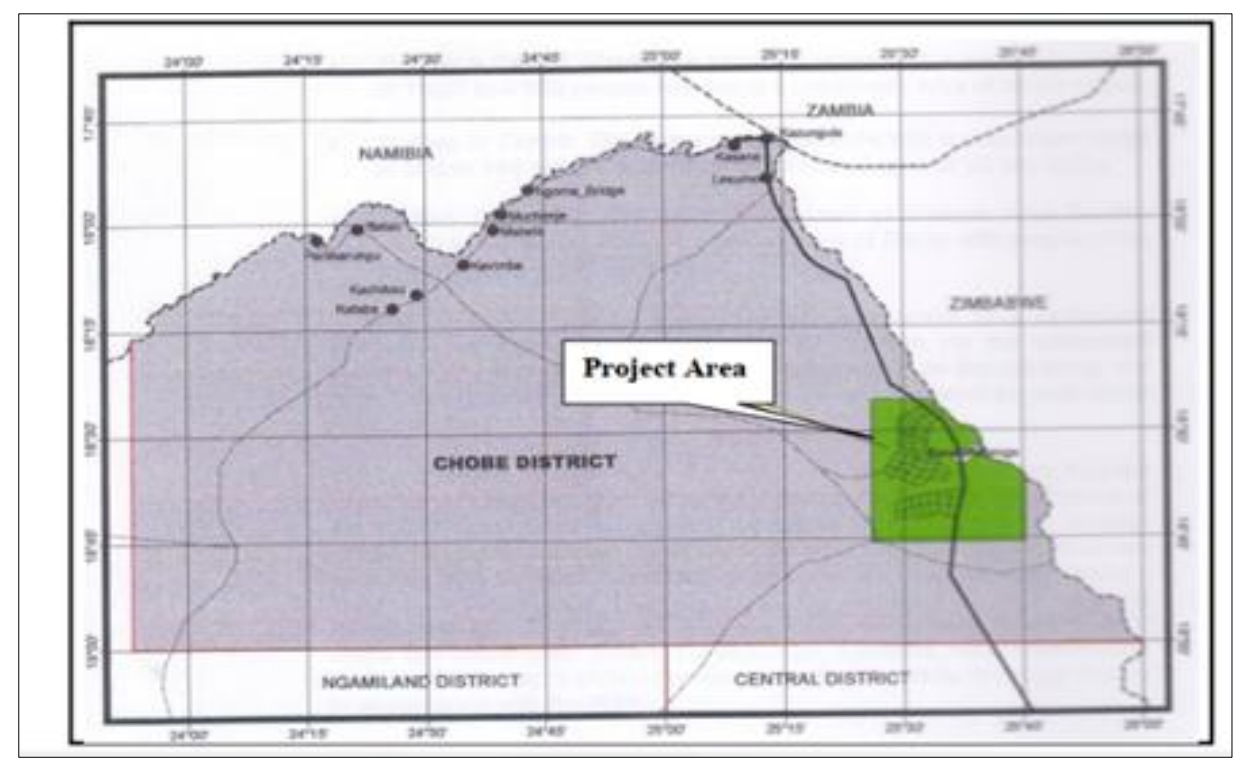

Figure 2 Detailed inset of Pandamatenga Farms

The Pandamatenga plains are underlain by basalt which occurs at the base of the black cotton soils. This basalt occurs subordinately with the sandstones. This basalt is mostly exposed around Pandamatenga and extends eastwards across the border into Zimbabwe [8]. The area is dominated by vertisolic clay soils, which are potentially good farming soils. The soils are characterized by very high clay contents dominated by expanding lattice clay minerals which give them their physical and chemical properties. The area is generally flat with a gentle slope and rain water flows following natural drainage routes [2].

\subsection{Population of the study and sampling techniques}

The target population for the study included smallholder rainfed farmers in the Pandamatenga region. A list of smallholder rainfed farmers was obtained from the Department of Crop Production at Pandamatenga. Simple random sampling was used to select 50 smallholder rainfed farmers from the list. After the selection of the sampled number of the smallholder rainfed farmers, they were visited for face- to- face interviews. The interviews were conducted using a structured questionnaire containing relevant questions which were answered by the respondents with the help of the researcher. To capture the perception of farmers towards CA technologies, CA issues such as benefits, constraints, and adoption problems, were included in the interviews. The respondents were asked to indicate their level of agreement with a given statement using a 5-point ordinal Likert scale ranging from "strongly agree" to "strongly disagree".

The socio - economic characteristics of the smallholder rainfed farmers included the following: land holding size (ha), labour availability, livestock possession, education level and farming experience. Demographic characteristics considered in this study were smallholder rainfed farmers' age, marital status, gender, and average number of members in the household.

\subsubsection{Data Analysis}

Descriptive statistics (means, percentages, median and interquartile range) from Statistical Package for the Social Sciences (SPSS) Version 22 [9] were used for data analysis. The t- test was used to compare the percentage differences of means of the continuous variables between adopters and non-adopters of CA technologies whereas the percentage difference of means for the categorised variables between adopters and non - adopters were compared using the Chi square test. Both tests were set at $5 \%$ level of significance.

The response to questions such as whether a smallholder rainfed farmer has used CA technologies or not could be yes or no, which is a typical case of dichotomous dependent variable. Hence a binary logistic regression model was used to estimate the farmer's probability or the odds of adopting CA practice given a set of socio-economic variables. Chi-square 
and likelihood estimation were used to test the significance of association between dependent and independent variables and the overall significance of the model.

\subsubsection{Logistic Regression Analysis}

According to Thomas [10],the logistic distribution for the adoption decision of CA can be specified as:

$P_{i}=\frac{1}{1+e^{-z i}}$

$P i$ is the probability of adopting CA for the ith farmer and ranges from 0 to 1.

$\mathrm{e}^{-}$represents the base of natural logarithms and $\mathrm{Zi}$ is the function of a vector of $\mathrm{n}$ explanatory variables and expressed as;

$z_{i}=\beta_{0}+\sum \beta_{i} X_{i}$

Where $\beta_{0}$ is the intercept and $\beta_{i}$ is a vector of unknown slope coefficients. The relationship between Pi and $X_{i}$ (and $X \mathrm{i}$ is the independence variable) which is non-linear, can be written as follows:

$P_{i}=\frac{1}{1+e^{-\beta 0+\beta i X i+\cdots \beta n X n}}$

The slopes tell how the log-odds in favour of adopting the technology changes as independent variables change. If Pi is the probability of adopting given technologies, then 1-Pi represents the probability of not adopting and can be written as:

$1-P i=\frac{1}{\left(1+e^{-z i}\right)}=\frac{e^{-z i}}{1+e^{-z i}}=\frac{1}{1+e^{z i}}$

Dividing equation (1) by equation (4) and simplifying gives:

$\frac{P_{i}}{1-P_{i}}=\frac{1+e^{z i}}{\left(1+e^{-z i}\right)}=e^{z}-$

Equation (5) indicates simply the odd-ratio in favour of adopting the technologies. It is the ratio of the probability that the farmer will adopt the technology to the probability that he will not adopt it. Finally, the logit model is obtained by taking the logarithm of equation (5) as follows:

$L_{i}=\mathrm{L}_{\mathrm{n}}\left[\frac{P_{i}}{1-P_{i}}\right]=z_{i}=\beta_{0}+\beta_{1} X_{1}+\beta_{2} X_{2}+\cdots \beta_{n} X_{n}$

Where $\mathrm{Li}$ is log of the odds ratio, which is not only linear in $\mathrm{X}$, but also linear in the parameters: Thus, if the stochastic disturbance error term Ui is taken into account, the logistic model becomes:

$z_{i}=\beta_{0}+\beta_{1} X_{1}+\beta_{2} X_{2}+\cdots \beta_{n} X_{n}+U_{i}$

Thus, the empirical model estimated in this study was specified as:

$z_{i}=\beta_{0}+\beta_{1} A G E+\beta_{2} G E N O F F+\beta_{3} E X P+\beta_{4} E D U O F F+\beta_{5} L A B P O+\beta_{6} T L T L U+\beta_{7} F S I Z E+\beta_{8} H E R B C D P R+\varepsilon$

Where:

$z_{i}$ is the logit, that is, the natural log of the odds of the smallholder rainfed farmer's decision to adopt CA technology given his / her set of explanatory socioeconomic factors.

Adoption of CA is a dichotomous decision variable represented by a value of 1 if a smallholder rainfed farmer is an adopter (practiced at least one of the stated technologies in the 2015/16 and 2016/17 cropping seasons) and a value of 0 otherwise (practised conventional tillage in the specified cropping seasons). 
AGE: Represented the age of the smallholder rainfed farmer in the Pandamatenga region at the time of the survey, measured in years. As the age of the farmer increases, the probability of using conservation agriculture is likely to decrease. This is because, with age a farmer can become more risk averse and then tend to be reluctant to new technologies. Thus, age is expected to have a negative influence on farmers' decision to adopt CA technologies in the study area.

GENOFF: Referred to gender of the smallholder rainfed farmer, which was measured as a dummy variable, coded with 1 if the farmer was a male and 0 if female. Males are in a better position to attend extension meetings in traditional set - ups and thus have more access to information on new agricultural technologies. Thus, adoption was expected to be higher among males compared to females.

EXP: Represented farming experience, the number of years the smallholder rainfed farmer has been farming, measured as a continuous variable. Experienced farmers are more perceptive of conservational benefits and hence are more receptive to new innovations. Farming experience is expected to positively influence farmers' decision to adopt conservation agriculture.

EDUOFF: Represented the education level of the smallholder rainfed farmer. It was measured as a dummy variable, coded with 1 if the farmer was literate (can only read and write), and 0 if illiterate. Exposure to education increases the ability of farmers to obtain, process and use information relevant to the adoption of new technology, thus level of education was expected to positively influence farmers' decision to adopt CA.

LABPO: Labour availability: It referred to the number of active family members between the age of 15 and 65 . It was measured as a continuous variable. A household with larger number of workers per hectare (unit) is more likely to be in a position to try and continue to use a potentially profitable innovation thus it is expected to positively influence farmers' decision to adopt CA.

TLTLU: Livestock possession: This variable was defined in terms of Total Livestock Unit (TLU), it was measured as a continuous variable. Households that have large number of livestock are expected to adopt innovation better than others who have less, thus it is expected to positively influence farmers' decision to adopt CA.

FSIZE: Total land holding size: In this study, farm size is defined as total farm size owned and rented by the household head in hectares. It was a continuous variable, measured by the number of hectares of the farm. Farmers with large hectarage under crop production have a greater incentive to invest in conservation agriculture. Farm size is expected to have a positive influence on household decision to adopt CA.

HERBCDPR: Herbicides price: This variable was measured on five-point scale based on farmers' perception as very expensive, expensive, moderately expensive, less expensive and not expensive. It was measured as categorical variable. It was hypothesized that the higher the perceived price of herbicide, the lower the likelihood of using CA.

\section{Results and discussion}

\subsection{Demographic and socio - economic characteristics of smallholder rainfed farmers}

These characteristics are shown in Table 1.

The mean age for adopters and non-adopters was estimated at 53 and 47 years respectively and the percentage difference of the mean age was statistically insignificant at 5\% level. It indicated that it was not one of the major factors that influenced smallholder rainfed farmers' as far as decision to adopt CA measures in the study area is concerned. This might be because there is a time in life of a farmer, when age would no longer matter as old age implies decreased interest in long term investment in farming. Jumbe \& Nyambose [11] also found out that age of household head was not significantly different for adopters and non-adopters of conservation agriculture in Malawi. In contrast, Ngombe et al. [12] reported that age of household head was statistically significant and it implied that older household heads are often associated with long years of experience in farming.

There was also no significant statistical difference in the average number of family members in the household between adopters and non-adopters of CA technologies. Average number of family members in the household was not statistically significant (Table 1). This might imply that not all the household members participate equally or are productive in the fields. Also, in the study area family labour was scarce due to migration to urban areas for jobs and 
schooling. In contrast, Fanuel [13] reported that adopters had a statistically significant household size compared to nonadopters in Zimbabwe.

Table 1 Demographic and socio-economic characteristics of adopters and non-adopters of CA practices in Pandamatenga

\begin{tabular}{|c|c|c|c|c|c|c|}
\hline Characteristics & Adopters & $\begin{array}{c}\text { Non- } \\
\text { adopters }\end{array}$ & $\begin{array}{c}\% \\
\text { Difference }\end{array}$ & \begin{tabular}{|c|} 
T- \\
Statistics
\end{tabular} & $\begin{array}{l}\mathrm{Chi}^{2} \\
\text { test }\end{array}$ & $\begin{array}{c}\text { P- } \\
\text { Value }\end{array}$ \\
\hline Average age of participant (years) & 53 & 47 & 11 & 1.229 & & \\
\hline Gender of participant (\% of male participant) & 76 & 35 & 54 & & 7.591 & $0.006^{* *}$ \\
\hline $\begin{array}{l}\text { Marital status of participant (\% of married } \\
\text { participant) }\end{array}$ & 67 & 9 & 86 & & 16.482 & $0.001^{* *}$ \\
\hline $\begin{array}{l}\text { Average number of members in the household } \\
\text { (family size) }\end{array}$ & 5.3 & 5.4 & 2 & -0.112 & & \\
\hline $\begin{array}{l}\text { Education level of participant (\% of participants } \\
\text { who can read and write) }\end{array}$ & 85.7 & 65.2 & 24 & & 11.780 & $0.001^{* *}$ \\
\hline $\begin{array}{l}\text { Labour Potential (Average number of adults who } \\
\text { can work in the field) }\end{array}$ & 1.2 & 1.83 & 54 & -1.365 & & \\
\hline Average number of livestock (TLU) & 5.6 & 1.38 & 75 & $2.309^{* *}$ & & \\
\hline Mean household land size (ha) & 16.7 & 7.20 & 57 & $2.654^{* *}$ & & \\
\hline $\begin{array}{l}\text { Average number of years in farming (farming } \\
\text { experience in years) }\end{array}$ & 9.1 & 8.43 & 7 & 0.317 & & \\
\hline
\end{tabular}

Table 1 also indicated that labour potential in terms of average number of adults working in the field was not statistically significant. Some farmers indicated that most of the activities that demanded labour such as weeding were tackled by the use of herbicides supplied by the Government for free. Jumbe \& Nyambose [11] also reported that labour potential between adopters and non-adopters was statistical insignificant. In contrast, Mlenga \& Maseko [14] found that a statistically significant increase in economically active family members contributed to agricultural labour.

The average number of years in farming (that is, farming experience) is another important variable that has a relationship to adoption. The average number of years in farming for adopters and non-adopters were estimated at 9 and 8 years, respectively. The percentage difference was not significant at $5 \%$ level of significance (Table 1). From the study area, most of the respondents were old people (especially the non-adopters) who had more than 10 years of farming and it is not easy for them to convert to modern agriculture practices. The findings of this study are contrary to those of Fanuel [13] who reported statistical significance between adopters and non-adopters, and it was further indicated that longer farming experience implied accumulated farming knowledge and skill which had contribution to adoption.

It is shown in Table 1 that gender of smallholder rainfed farmers between adopters and non-adopters of CA technologies was such that, on average, $76 \%$ of the adopters were male. Likewise, 35\% of the non-adopters were male. Results revealed that percentage difference (of 54\%) between male adopters and non-adopters of CA was statistically significant at $5 \%$ level. This might be due to males having better chances of access to information as compared to their female counterparts in the study area. The findings of this study are in contrast with those of Jumbe \& Nyambose [11] who reported no statistical significance in gender between adopters and non-adopters (Table 1).

Table 1 also indicates that $67 \%$ of the adopters were married while only $9 \%$ of the non-adopters were married. The percentage difference (86\%) of married smallholder rainfed farmers between the two groups was statistically significant at 5\% level. This implies that married couples are in a better position to consult with each other to make good decisions. Ngombe et al. [12] reported similar significant results between adopters and non-adopters of CA. They reasoned that married farmer had higher social connections and interactions with other farm households thus providing better access to information about agricultural technologies.

The education level, measured in terms of average number of smallholder farmers who were able to read and write between adopters and non-adopters was statistically significant at 5\% level. Almost $86 \%$ of the adopters were able to 
read and write compared to $65.2 \%$ for non - adopters. This implies that education is an important household characteristic for increasing the transfer of relevant information to the farmers. Education is one of the significant variables for enhancing the adoption of CA $[6,15]$.

Table 1 also revealed that the average number of livestock (TLU) was a statistically significant variable for enhancing adoption. Similar results have been reported elsewhere [6, 7]. This study also revealed that the mean land size difference between adopters and non-adopters was statistically significant implying that ownership of large areas of land was vital for adopting CA in the study area (Table 1). Similar results were reported by Fadare et al. [15]. In contrast, Ngombe et al. [12], reported that land size was not statistically significant between adopters and non-adopters of CA.

\subsection{Smallholder rainfed farmers' perceptions and level of acceptance of CA technologies}

Table 2 presents a summary of farmers' perceptions toward CA in the study area.

Table 2 Summary on farmers' perceptions toward CA in the study area

\begin{tabular}{|l|c|c|c|}
\hline & \multicolumn{2}{|c|}{ Farmers' Agreement Score } \\
\hline Statement & Agree & Disagree & Neutral \\
\hline I have full knowledge of CA technologies & $10(23 \%)$ & $19(43 \%)$ & $15(34 \%)$ \\
\hline CA technologies can be beneficial to farmers & $20(46 \%)$ & $6(14 \%)$ & $18(41 \%)$ \\
\hline Advantages of CA & & & \\
\hline Increase yield & $20(46 \%)$ & $6(14 \%)$ & $18(41 \%)$ \\
\hline Increase income & $20(46 \%)$ & $6(14 \%)$ & $18(41 \%)$ \\
\hline Prevent soil erosion & $10(23 \%)$ & $6(14 \%)$ & $28(64 \%)$ \\
\hline Disadvantages of CA & & & \\
\hline Labour intensive & $24(55 \%)$ & $9(21 \%)$ & $11(25 \%)$ \\
\hline Lack of farm implements is limiting CA & $40(91 \%)$ & $2(5 \%)$ & $2(5 \%)$ \\
\hline Having tried CA in the farm, will you continue to adopt? & $34(77 \%)$ & $7(16 \%)$ & $3(7 \%)$ \\
\hline
\end{tabular}

Only $23 \%$ of the smallholder rainfed farmers had full knowledge about CA while $43 \%$ were not aware about CA technologies and $34 \%$ were uncertain. From the descriptive statistics, most of the smallholder rainfed farmers were not certain about knowing CA technologies. This is shown by the median of 3 and interquartile range of 1 (Table 3 ).

Table 3 Descriptive statistics for farmers' perception toward CA technology

\begin{tabular}{|l|c|c|}
\hline Statement/question & Median & Interquartile range \\
\hline I have full knowledge of CA technologies & 3 & 1 \\
\hline I have experience of CA technologies & 3 & 1 \\
\hline CA technologies can be beneficial to farmers & 3 & 1 \\
\hline CA can be beneficial in increasing yield & 3 & 1 \\
\hline CA can be beneficial in increasing income & 3 & 1 \\
\hline Ca can prevent soil erosion & 2 & 0 \\
\hline CA can be disadvantageous as it is labour intensive & 2 & 1 \\
\hline Lack of farm implements is limiting CA & 2 & 0 \\
\hline Having tried CA in the farm, will you continue to adopt? & 2 & 0 \\
\hline
\end{tabular}

Key: 1-Strongly agree; 2- agree, 3- Neutral, 4- disagree, 5- strongly disagree 
This might be due to farmers' understanding of CA in different ways. Some of them reported that they only saw the practices on television and had never practiced it in their farms to appreciate its benefit. Forty - six percent of smallholder rainfed farmers agreed that CA technologies could be beneficial to them as it increases yield and income while $41 \%$ were uncertain because they had not practiced CA to see its benefit. The descriptive statistics shows a median of 3 and interquartile of 1 (Table 3). In preventing soil erosion, 64\% of the smallholder rainfed farmers were uncertain with a median score of 3 . The response of farmers to CA technologies being labour intensive was that more than $50 \%$ agreed with a median of 2 . Ninety-one percent of farmers agreed that lack of farming implements was a limiting factor in CA with a median of 2 and interquartile range of 0 . For the incorporation of CA in the future, smallholder rainfed farmers showed positive attitude towards adopting the technology as 77\% responded with "agree" at the median of 2 (Table 3 )

\subsection{Social-economic factors influencing farmers' decisions to adopt various CA technologies}

Table 4 presents socio-economic variables, the logistic regression estimates, odds ratios, and significant values at $1 \%$ and $5 \%$ levels of significance. Results showed that the Log-Likelihood function was statistically significant at $1 \%$ level. This suggests that when variables are taken together, they strongly influence farmers' decision to adopt CA technologies in the study area. Likewise, $\chi 2$ statistic of 34.284 showed that the overall model was significant at $1 \%$ level signifying fitness of the model and implying the explanatory variables relevant in explaining smallholder rainfed farmers' decision to adopt CA technologies in the study area.

Table 4 Binary logit model estimates (Estimated Log Odds and Odds Ratios)

\begin{tabular}{|l|c|c|c|c|}
\hline \multicolumn{1}{|c|}{ Variables } & Coefficients & Std. Error & Sig. & Odds ratio \\
\hline Constant & -3.135 & 2.439 & 0.199 & 0.043 \\
\hline AGE & 0.044 & 0.040 & 0.273 & 1.045 \\
\hline GENOFF & -2.757 & 1.316 & $0.036^{* *}$ & 0.063 \\
\hline EXP & 0.018 & 0.092 & 0.845 & 1.018 \\
\hline EDUOFF & -2.217 & 1.662 & 0.182 & 0.109 \\
\hline LABPO & -0.653 & 0.582 & 0.262 & 0.520 \\
\hline TLTLU & 0.498 & 0.316 & 0.115 & 1.645 \\
\hline FSIZE & 0.267 & 0.131 & $0.042^{* *}$ & 1.306 \\
\hline HERBCDPR & -0.007 & 1.699 & 0.997 & 0.993 \\
\hline Log - Likelihood & 26.622 & & & \\
\hline$X^{2}$ & 34.284 & & & \\
\hline Probability of $X^{2}$ & $0.000^{* * *}$ & & & \\
\hline \multicolumn{2}{|c|}{ Source model output: ${ }^{* * *}$ Significant at $1 \%{ }^{* *}$ Significant at 5\% } \\
\hline
\end{tabular}

Table 4 shows that gender of participants and farm size were statistically significant factors in influencing smallholder rainfed farmers' decision to adopt CA technologies in the study area. The negative sign of the coefficient on this variable implied a negative association between gender and farmers' decision to adopt CA technologies. Male farmers were 0.063 times less likely to adopt CA technologies than females in Pandamatenga. Adoption of CA technologies was expected to be higher among males compared to females. The results however, showed that males were less likely to adopt than females in the study area (Table 4). This might be because, in the study area, land preparation for CA technologies is mainly done by females during dry season. During this period, men would be busy with off -farm activities which would hinder them from participating in the dry land preparation hence reducing their probability of adopting CA technologies in the study area. The results are consistent with those of Phiri [16] who established that more females increased the probability of adopting CA technologies. In contrast, Jumbe \& Nyambose [11] reported that males were more likely to adopt CA technologies than females.

Farm size positively influenced the odds of smallholder rainfed farmers' decision to adopt CA technologies in the study area and was statistically significant at $5 \%$ level. An increase in the size of land by one ha, for instance, would increase the odds of adopting a CA practice by 1.306. Farmers with large hectarage under crop production have a greater 
incentive to invest in CA. It was shown earlier in this paper (Table 1) that adopters had more owned land, on average, than non-adopters and the difference was statistically significant. This is supported by various authors $[6,11,15]$.

Age, farming experience and total owned livestock were found to have positive association with farmer's decision to adopt CA technologies but their respective individual influences were not significant at both $1 \%$ and $5 \%$ levels of significance. Education level, labour potential and herbicides price were found to have a negative association with farmer's decision to adopt CA but their respective individual influences were also not statistically significant at both $1 \%$ and 5\% levels (Table 4).

\section{Conclusion}

The following conclusions are drawn from the study:

- The demographic and socio-economic characteristics of smallholder rainfed farmers comprising gender, marital status, education level, livestock numbers and land size were associated with adoption of CA technologies in Pandamatenga.

- The binary logit regression model significantly strengthened the influence of gender and land size (as explanatory factors) on smallholder rainfed farmers' decision to adopt various CA technologies in Pandamatenga.

- Smallholder rainfed farmers had a positive perception and high level of acceptance of CA technologies in Pandamatenga.

\section{Compliance with ethical standards}

\section{Acknowledgments}

The support and cooperation of Pandamatenga personnel from the Departments of Crop Production and Agricultural Research of the Ministry of Agriculture Development and Food Security, who provided relevant secondary data and facilitated field work, is highly appreciated. The authors lastly express their gratitude to sampled smallholder rainfed farmers for their cooperation during data collection.

\section{Disclosure of conflict of interest}

We the authors of this paper hereby declare that there are no competing interests in this publication.

\section{References}

[1] Statistics Botswana. Annual Agricultural Survey Report 2013. Statistics Botswana, Gaborone, Botswana. 2015.

[2] Tapela M, Kayombo B, Pule - Meulenberg F. Potential for No-Tillage Agriculture in the Pandamatenga Vertisols of Botswana. Agricultural Mechanization in Asia, Africa and Latin America. 2007; 38(2): 42-47.

[3] Food and Agriculture Organization of the United Nations (FAO). What is conservation Agriculture? 2016.

[4] Pardo MT, Ristori G, D’Acqui LP, Almendros G. An Assessment of Soil Fertility and Agronomic Constraints in Southern African Savannas: a Case Study of the Pandamatenga Area, Botswana. South African Geographical Journal. 2012; 85(1): 35-41.

[5] Araya T, Nyssen J, Govaerts B, Deckers J, Sommer R, Bauer H, Gebrehiwot K, Cornelis WM. Seven years resourceconserving agriculture effect on soil quality and crop productivity in the Ethiopian drylands. Soil and Tillage Research. 2016; 163: 99-109.

[6] Bazezew HA. Adoption of conservation agricultural practices: The case of Dangila District , Amhara Region , Ethiopia. Global Science Research. 2015; 3(9): 295-307.

[7] Kassie M, Jaleta M, Shiferaw B, Mmbando F, Muricho G. Plot and household-level determinants of sustainable agricultural practices in rural Tanzania. Environment for Development. 2012;(12-02): 41.

[8] Centre for applied Research (CAR). Environmental and Social Impact Assessment of the Zambezi Integrated AgroCommercial Development Project Phase 1. Gaborone, Botswana. 2009. 
[9] IBM Corp. SPSS Statistics for windows version 22. IBM Corporation, New York. 2013.

[10] Thomas RL. Modern Econometrics: An introduction, China. Prentice Hall. 1996.

[11] Jumbe CBL, Nyambose WH. Does Conservation Agriculture Enhance Household Food Security? Evidence from Smallholder Farmers in Nkhotakota in Malawi. Sustainable Agriculture Research. 2016; 5(1): 118-128.

[12] Ngombe J, Kalinda T, Tembo G, Kuntashula E. Econometric Analysis of the Factors that Affect Adoption of Conservation Farming Practices by Smallholder Farmers in Zambia. Journal of Sustainable Development. 2014; 7(4): 124-138.

[13] Fanuel M. Determinants of Adoption of Conservation Agriculture by Communal Farmers in Masvingo District, Zimbabwe. University of Zimbabwe. 2013.

[14] Mlenga DH, Maseko S. Factors Influencing Adoption of Conservation Agriculture : A Case for Increasing Resilience to Climate Change and Variability in Swaziland. Journal of Environment and Earth Science. 2015; 5(22): 16-25.

[15] Fadare OA, Akerele D, Toritseju B. Factors Influencing Adoption Decisions of Maize Farmers in Nigeria. International Journal of Food and Agricultural Economics. 2014; 2(3): 45-54.

[16] Phiri C. Factors affecting the adoption of Conservation Agriculture among small scale farmers in Zambia's Mumbwa District. University of Zambia. 2013. 